\title{
An archival review of preferred methods for theory building in follower research
}

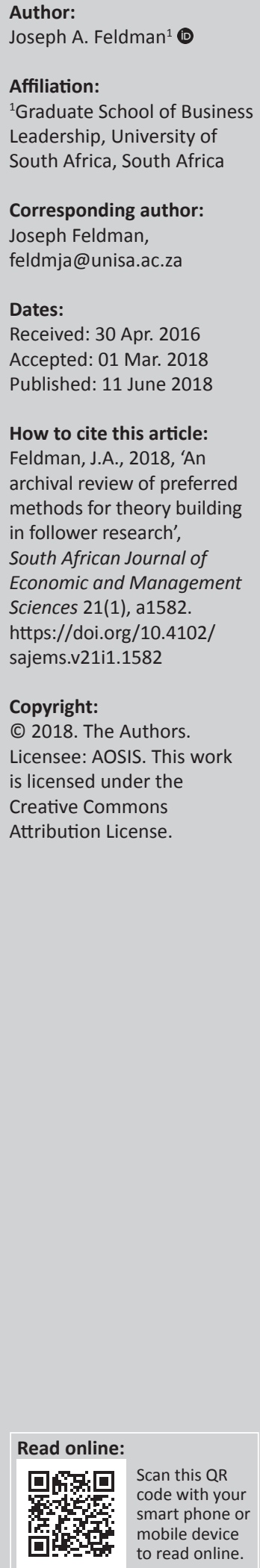

Aim: The purpose of this research was to delineate methodological trends in articles published both internationally and locally that will reveal the extent of new theory building.

Setting: The research strategy and methodology examined trends in theory building over a 52-year period (1962-2014).

Method: An archival review of the published literature was conducted and each article was examined to identify the general research method employed. The chi-square test was used to determine whether there is a significant difference between the expected frequencies and the observed frequencies in one or more of four categories.

Results: The archival data indicate that articles published over the past 52 years in major international and South African journals are skewed towards quantitative and conceptual research. This implies that researchers in leadership studies employed qualitative and mixed methodologies in their work less often than quantitative and conceptual methodologies.

Conclusion: This trend has implications for the development of leadership-followership research. Research methods should be used with mindfulness, with qualitative methods being used to observe social and human problems, followed by quantitative methods to test inductively formulated followership theories. It is particularly important, in the context of diverse cultures, to note that local attempts to formulate authentic theory development will remain difficult and unsuccessful until endogenous management systems are established and institutionalised. This is very important for scholars who believe that an affinity for qualitative methodology affords the opportunity for emic research rather than merely for testing theories and constructs that may not capture local followership phenomena.

\section{Introduction}

An informal preliminary literature review by the author of this research revealed that the concept of followership has, until now, received very little attention in leadership studies. In most leadership studies, very little or no reference is made to followership or to its role in leadership-followership dynamics. A need has now emerged to build followership theory that reflects the unique reality of different cultures and contexts in the global and South African leadership-followership environment as they relate to one another, that is, building follower capacity that is understood by leaders. Kelley (1992) states that, in general, the views of leadership in various leadership studies are more developed and advanced compared with the views on followership.

Vecchio (2002:659) states that 'a number of models exist that detail dimensions of leadership, whereas there are no formal models that detail styles or dimensions of followership'. As a result of the conclusions reached by researchers such as Vecchio, research with a follower-centred approach has been receiving increased attention. Evidence by Eden and Leviathan (1975:740) is enlightening: 'It is evident from the results of the study that the leadership factors are in the mind of the respondent' (being the follower). This means that the chance to emerge as, and remain, an effective leader does not depend solely on the leader's own behaviour, but also on followers' accessing of information to make attributions about the leader. Such approaches indicate that the evaluation and acceptance of a leader in a specific situation is determined by followers' mindsets, which consist of assumptions, beliefs and expectations regarding the causes, nature and the consequences of leadership, or, in other words, their implicit leadership theories, which, in fact, can be thought of as their follower theories. 


\section{Literature review}

The awareness of the lack of sustained research of followership to complement leadership research, prompted by Vecchio, Eden and Leviathan above, was also felt by Joubert and Feldman (2017). Their research findings achieved a deeper appreciation of followers' epistemological and ontological views, within a specified context, and were supported by a common need to achieve organisational safety objectives. A practical managerial benefit was found in the insights presented by followers of leadership, one which might also possibly bolster leadership development and training needs, along with the training and advancement of followers.

Harms and Spain (2014) reflect on an alternative, yet relevant, view. They direct attention towards the perceptual biases held by followers as a potentially fruitful topic for future research in the field of leadership-followership dynamics. Leaders become effective or ineffective because of how followers however idiosyncratically - perceive them. Perceptual biases can lead to negative or positive views of leader behaviour. Followers view leaders differently, depending on positive (prototypical) or negative (anti-prototypical) leader behaviour.

Against the background of the literature above, Petros Malakian completes the rationale for follower research in his 2014 article. Its essence is conveyed below.

Malakian (2014) refers to thirteen leadership approaches and points out how each of the studies omits the follower dynamic in its thesis:

The Trait Approach, the earliest systematic study of leadership (Bass 1981; Lord, De Vader \& Alliger 1986), does not address followership. Gardner et al. (2005) goes on to state that one of the evidences of this omission is the complementary list of leadership traits with no follower traits developed from 1948 to 2004, with the exception of authentic leadership, where the leader and follower development is considered.

The Skills Approach, which aims to solve complex problems in organisational leadership (Katz 1974; Mumford et al. 2000), omits the leader-follower dynamic as a subject of study.

The Style Approach, which defines leadership as relational and task-oriented behaviour (Ohio State and Michigan State studies) - and which also embraces the managerial or leadership grid (Blake \& Mouton 1985) in order to explain the importance of concern for people and concern for productivity - is also a leader-centred approach.

The Situational Approach, with its four leadership styles (Hersey, Blanchard \& Johnson 2012), is also a leader-oriented study because follower-styles, and how they may affect the leader's behaviour, have not been identified.

The Contingency Theory, being a leader-match theory (Fiedler 1964, 1967; Fiedler \& Garcia 1987), assumes that leadership effectiveness is contingent on leadership style and leadership situation. It thus offers no discussion on follower style and its impact on leadership effectiveness.

The Path-goal Theory is concerned with the motivation of subordinates towards the goal set forth by the leader of the organisation (Evans 1970; House 1971; House \& Dessler 1974). The goals of the organisation are not necessarily discussed and mutually agreed upon by the leader and the follower.

Leader-Member Exchange Theory (LMX theory), which puts sole emphasis on leader-follower interactions as a dyadic relationship within a three-phase developmental process (stranger, acquaintance and partner) (Danserieu. Graen \& Haga 1975; Graen \& Uhl-Bien 1995), seems to segregate followers into two types of groups: in-groups and outgroups. The LMX theory can thus be accused of favouritism and unfairness. Phillips and Bedeian (1994) commented on leader-follower attribution exchanges that have been conducted. Attitudinal similarity and introversion or extroversion measures were inferred to be more positively related to leader-member exchange level than follower growth, need strength and locus of control. Other predictors are also employed as part of LMX theory, along with diverse samples and measurement procedures intended to lead to a complete understanding of the leader-member exchange model.

Transformational Leadership is also concerned with the leader's behaviours and can be viewed as elitist and anti-democratic (Avolio \& Gibbons 1988).

Team Leadership allows for functional flexibility among team members in that they choose their own teammates from among the members of the entire team (Fisher 1985; Hackman 2002; Kinlaw 1998). This approach tends to focus more on the leader's decision-making towards team effectiveness through internal or external leadership interventions.

Servant Leadership. The focus here seems to remain on the one who becomes a leader through his or her service. It still does not show how one can be a servant follower.

Leadership Ethics Approach. Here, the leader is at the centre of the research attention, which raises the question of how the followers' ethical behaviour can be discounted (Hollander 1995).

Authentic Leadership. In this theory, followership is fully present in research and the followers' emotional reaction to the leader's inauthentic behaviour has been studied alongside leadership (Eagly 2005; Gardener et al. 2005; George \& Sims 2007). Most scholars, however, still ascribe leadership and followership to two separate human identities. Thus, the theory seems to hold a static view of the leader and the follower. 
Followership does serve as the subject or study-matter in the following research:

Singh and Bodhania (2013) conducted their research from a South African point of view and state that, while leadership and leaders are an important part of organisational life, they cannot exist without followers. They also express their surprise that such a great disparity exists between the volume of existing leadership and followership literature, with the volume of leadership literature far outweighing that of followership. Scholars have challenged the assumption that management (by implication leadership-followership) theories formulated in one country are applicable universally. Research in one country cannot be generalised directly to other countries.

Greyvenstein and Celliers (2012) used qualitative descriptive research, titled: 'Followership's experiences in organizational leadership'. This approach presupposes that leaders are more effective in their roles when they understand their own psychological world, as well as that of their subordinates, and that the emotional responses and habitual patterns of behaviour of both leaders and followers are the result of strong influences from past experiences. The follower does not necessarily seem to be the subject of study in relation to the leader. They found that six themes manifested, namely a negative leadership view, idealisation of the past and blaming the present, obsession with race and gender, constantly changing identity, unfinished business and the future, and 'cope and hope'. From a followership in leadership studies view, this research can be credited with at least posting the following practical managerial implications:

- Leadership seems to focus more on business than on followership issues and this leads to followers feeling disregarded and de-authorised. As a result, followers withhold authorisation from leadership which, in turn, may be instrumental in leadership's difficulties in managing change and transformation effectively.

- Leadership development needs to incorporate the selfauthorisation of leaders as well as the invitation of authorisation by leaders.

Conclusion: There is a gap in the existing research on the leadership-followership continuum. Research on followers is in its beginning stages and is outweighed by research on leadership. In addition, no knowledge exists on the prevalence of research paradigms and methods in followership.

\section{Problem statement}

The literature study, which reflects the gaps in archival studies of followership research in international and South African literature, presents the opportunity to address the problems, which may be presented as: the very limited prevalence of followership research and knowledge of the preferred methods used in the research.

\section{Purpose and objectives of the research}

Against the background of the need to address the problem statement above, the purpose of this study is to determine, firstly, the extent to which theory-building trends are occurring in the field of followership in organisations. More specifically, the objective is to delineate methodological trends in articles published in international as well as South African leadership-followership research as an indicator of new theory development.

Secondly, the other objective of this study is to review a sample of studies as the most likely sources from which theorists would publish theory-building research.

This research strategy and methodology examines trends in theory building in followership over a 52-year period (1962-2014).

\section{Research design Method}

The study reviewed research published from 1962 to 2014 in journals that were selected on the basis of the following keywords: followership; follower attributes; follower perceptions of leadership; follower attributions of leadership; leader attributes; leadership behaviours; leadership attributions about followers.

An archival review of the published literature was conducted and each article listed in Table 1 was examined to identify the general research method employed. The categories used to assist in the classification of the articles published were: 'conceptual', 'quantitative', 'qualitative' and 'mixed'. Articles were defined as 'conceptual' if they were reviews of literature, essays or systematic attempts to explain the explicit and implicit use of concepts. These articles did not involve the collection of empirical data.

'Quantitative' research relates to a nomothetic or etic science, based on probabilities derived from the study of large numbers of randomly selected cases (Cresswell 2003).

'Qualitative' research was used if data collection occurred through means such as case studies, interviews, narrative studies, ethnography, archival retrieval, participant observation and a variety of other qualitative methods.

A 'mixed' research method, also known as triangulation, is used if a study employed both 'quantitative' and 'qualitative' design techniques (Opperman 2000).

To continue with analysis of prevalence of categories, the interrater reliability was found to be $95 \%$. Interrater reliability addresses the consistency among researchers in assigning each article, based on consensus, to the four different types of research. It does not assess the validity, which would be concerned with the classification system itself. However, a minimum content validity was achieved by using wellestablished definitions of each type of research article. 
TABLE 1: Frequencies on measures used.

\begin{tabular}{|c|c|c|c|c|}
\hline Research topic & Conceptual & Quantitative & Qualitative & Mixed \\
\hline Prilipco, Antelo \& Henderson (2011) & - & Survey; correlation procedures & - & - \\
\hline Antelo (2010) & - & $\begin{array}{l}\text { Survey; variability; correlation } \\
\text { coefficients }\end{array}$ & - & - \\
\hline Jaussi \& Dionne (2004) & - & Experimental hypothesis testing & - & - \\
\hline Felfe \& Schyns (2009) & - & $\begin{array}{l}\text { NEO-PI personality assessment; } \\
\text { hypothesis testing }\end{array}$ & - & - \\
\hline Hollander (1995) & Exposition of literature & - & - & - \\
\hline Thoroughgood, Hunter \& Sawyer (2011) & - & $\begin{array}{l}\text { Hypothesis testing; various } \\
\text { manipulations }\end{array}$ & - & - \\
\hline Phillips \& Bedeian (1994) & - & Survey; various statistical methods & - & - \\
\hline Greyvenstein \& Celliers (2012) & - & - & $\begin{array}{l}\text { Qualitative; descriptive } \\
\text { psychodynamic listening post }\end{array}$ & - \\
\hline Ridley, Chatterley \& Soutar (1998) & - & $\begin{array}{l}\text { Survey; descriptive; multivariate } \\
\text { analysis }\end{array}$ & - & - \\
\hline Mossholder, Niebuhr \& Norris (1990) & - & Moderated regression analysis & - & - \\
\hline Wiley (1997) & - & Surveys; descriptive statistics & - & - \\
\hline Lee (2013) & - & Causality; structural equation modelling & - & - \\
\hline Parmer, Green, Duncan \& Zarate (2013) & - & Surveys; structural equation modelling & - & - \\
\hline Schyns \& Hansbrough (2008) & $\begin{array}{l}\text { Model of attribution mistakes } \\
\text { through propositions for research }\end{array}$ & - & - & - \\
\hline Peus, Braun \& Frey (2012) & $\begin{array}{l}\text { Multilevel model adverse } \\
\text { leadership: } 13 \text { propositions for } \\
\text { research }\end{array}$ & - & - & - \\
\hline Kilburn (2010) & $\begin{array}{l}\text { Research comparisons of follower } \\
\text { typologies: } 2 \text { propositions }\end{array}$ & - & - & - \\
\hline Clifford \& Cohn (1964) & - & Hypothesis testing & - & - \\
\hline Malakian (2014) & Theoretical article & - & - & - \\
\hline Bligh et al. (2007) & - & Descriptive statistics; regression analysis & - & - \\
\hline Steinbauer et al. (2013) & - & $\begin{array}{l}\text { Structural equation modelling; } \\
\text { moderated regression analysis }\end{array}$ & - & - \\
\hline Lapierre et al. (2012) & $\begin{array}{l}\text { Model of manager's behaviour: } 8 \\
\text { propositions for research }\end{array}$ & - & - & - \\
\hline Harms \& Spain (2014) & Commentary & - & - & - \\
\hline
\end{tabular}

Note: Please see the full reference list of the article, Feldman, J.A., 2018, 'An archival review of preferred methods for theory building in follower research', South African Journal of Economic and Management Sciences 21(1), a1582. https://doi.org/10.4102/sajems.v21i1.1582, for more information.

\section{Analyses}

On completion of categorisation, a statistical analysis was performed to ascertain whether there were significant differences in the research methods utilised. A chi-square analysis was performed, which allows for a test of differences in cell frequencies of each of the different types of methods (Gravetter \& Wallnau 2000).

The chi-square test is used to determine whether there is a significant difference between the expected frequencies and the observed frequencies in one or more categories, that is, the chi-square goodness of fit test allows us to test whether the observed proportions for a categorical variable differ from hypothesised proportions; if the four categories above are postulated to be in equal proportions, then the hypothesised proportion is $25 \%$, for instance.

For this research, the null hypothesis is that the proportion of conceptual studies, the proportion of quantitative studies, the proportion of qualitative studies and the proportion of joint or mixed studies are equal, as opposed to the alternative, which is that at least two types will differ in their proportions.
The decision rule was to reject the null hypothesis if the p-value (of the chi-square statistic) is less than the level of significance, which is 0.05 . Alternatively, the null hypothesis will be accepted if the test statistic (chi-square) is greater than the critical value.

\section{Ethical consideration}

The study was cleared ethically by University of South Africa (UNISA) School of Business Leadership.

\section{Results}

Based on the analysis in the table, the frequencies of the theory-building research methods in follower research are found to be:

- Conceptual: $27 \%$

- Quantitative: 59\%

- Qualitative: 7\%

- Mixed: $7 \%$

The chi-square value 300, which is very high (thus, reject the null hypothesis) and that is highly significant, meaning reject 
TABLE 2: TYPE * proportion cross-tabulation.

\begin{tabular}{|c|c|c|c|c|c|c|}
\hline \multirow[t]{2}{*}{ Type } & \multirow[t]{2}{*}{ Variable } & \multicolumn{4}{|c|}{ Proportion } & \multirow[t]{2}{*}{ Total } \\
\hline & & 1 & 2 & 3 & 4 & \\
\hline \multirow[t]{5}{*}{ Conceptual } & Count & 27 & 0 & 0 & 0 & 27 \\
\hline & Expected count & 7.3 & 15.9 & 1.9 & 1.9 & 27.0 \\
\hline & $\%$ within TYPE & $100.0 \%$ & $0.0 \%$ & $0.0 \%$ & $0.0 \%$ & $100.0 \%$ \\
\hline & $\begin{array}{l}\% \text { within } \\
\text { proportion }\end{array}$ & $100.0 \%$ & $0.0 \%$ & $0.0 \%$ & $0.0 \%$ & $27.0 \%$ \\
\hline & $\%$ of total & $27.0 \%$ & $0.0 \%$ & $0.0 \%$ & $0.0 \%$ & $27.0 \%$ \\
\hline \multirow[t]{5}{*}{ Quantitative } & Count & 0 & 59 & 0 & 0 & 59 \\
\hline & Expected count & 15.9 & 34.8 & 4.1 & 4.1 & 59.0 \\
\hline & $\%$ within TYPE & $0.0 \%$ & $100.0 \%$ & $0.0 \%$ & $0.0 \%$ & $100.0 \%$ \\
\hline & $\begin{array}{l}\% \text { within } \\
\text { proportion }\end{array}$ & $0.0 \%$ & $100.0 \%$ & $0.0 \%$ & $0.0 \%$ & $59.0 \%$ \\
\hline & $\%$ of total & $0.0 \%$ & $59.0 \%$ & $0.0 \%$ & $0.0 \%$ & $59.0 \%$ \\
\hline \multirow[t]{5}{*}{ Qualitative } & Count & 0 & 0 & 7 & 0 & 7 \\
\hline & Expected count & 1.9 & 4.1 & 0.5 & 0.5 & 7.0 \\
\hline & $\%$ within TYPE & $0.0 \%$ & $0.0 \%$ & $100.0 \%$ & $0.0 \%$ & $100.0 \%$ \\
\hline & $\begin{array}{l}\% \text { within } \\
\text { proportion }\end{array}$ & $0.0 \%$ & $0.0 \%$ & $100.0 \%$ & $0.0 \%$ & $7.0 \%$ \\
\hline & $\%$ of total & $0.0 \%$ & $0.0 \%$ & $7.0 \%$ & $0.0 \%$ & $7.0 \%$ \\
\hline \multirow[t]{5}{*}{ Joint/mixed } & Count & 0 & 0 & 0 & 7 & 7 \\
\hline & Expected count & 1.9 & 4.1 & 0.5 & 0.5 & 7.0 \\
\hline & $\%$ within TYPE & $0.0 \%$ & $0.0 \%$ & $0.0 \%$ & $100.0 \%$ & $100.0 \%$ \\
\hline & $\begin{array}{l}\% \text { within } \\
\text { proportion }\end{array}$ & $0.0 \%$ & $0.0 \%$ & $0.0 \%$ & $100.0 \%$ & $7.0 \%$ \\
\hline & $\%$ of Total & $0.0 \%$ & $0.0 \%$ & $0.0 \%$ & $7.0 \%$ & $7.0 \%$ \\
\hline \multirow[t]{5}{*}{ Total } & Count & 27 & 59 & 7 & 7 & 100 \\
\hline & Expected count & 27.0 & 59.0 & 7.0 & 7.0 & 100.0 \\
\hline & $\%$ within TYPE & $27.0 \%$ & $59.0 \%$ & $7.0 \%$ & $7.0 \%$ & $100.0 \%$ \\
\hline & $\begin{array}{l}\% \text { within } \\
\text { proportion }\end{array}$ & $100.0 \%$ & $100.0 \%$ & $100.0 \%$ & $100.0 \%$ & $100.0 \%$ \\
\hline & $\%$ of total & $27.0 \%$ & $59.0 \%$ & $7.0 \%$ & $7.0 \%$ & $100.0 \%$ \\
\hline
\end{tabular}

TABLE 3: Chi-square tests.

\begin{tabular}{lccc}
\hline Variable & Value & df & Asymp. Sig. (2-sided) \\
\hline Pearson Chi-Square & $300.000^{\text {a }}$ & 9 & 0.000 \\
Likelihood ratio & 207.424 & 9 & 0.000 \\
Linear-by-linear & 99.000 & 1 & 0.000 \\
association & 100 & - & - \\
$N$ of valid cases & & & \\
\hline
\end{tabular}

TABLE 4: Symmetric measures.

\begin{tabular}{llcccc}
\hline Variable & Correlation & Value & $\begin{array}{c}\text { Asymptotic } \\
\text { standard error }\end{array}$ & $\begin{array}{c}\text { Approximate } \\
T^{\mathrm{b}}\end{array}$ & $\begin{array}{c}\text { Approximate } \\
\text { significance }\end{array}$ \\
\hline $\begin{array}{l}\text { Interval by } \\
\text { interval }\end{array}$ & Pearson's $R$ & 1.000 & 0.000 & 3260982276.431 & $0.000^{\mathrm{c}}$ \\
$\begin{array}{l}\text { Ordinal by } \\
\text { ordinal }\end{array}$ & $\begin{array}{l}\text { Spearman } \\
\text { correlation }\end{array}$ & 1.000 & $0.000^{\mathrm{c}}$ & - & - \\
$\begin{array}{l}N \text { of valid } \\
\text { cases }\end{array}$ & - & 100 & - & - & - \\
\hline
\end{tabular}

a, Not assuming the null hypothesis

b, Using the asymptotic standard error assuming the null hypothesis

c, Based on normal approximation

the null hypothesis and conclude there is evidence to show that the proportions are not the same or there is association between type and proportion.

\section{Conclusions}

The archival data indicate that articles published over the past 52 years in major international journals are skewed towards 'quantitative' and 'conceptual' research. This implies that researchers in leadership studies employed 'qualitative' and

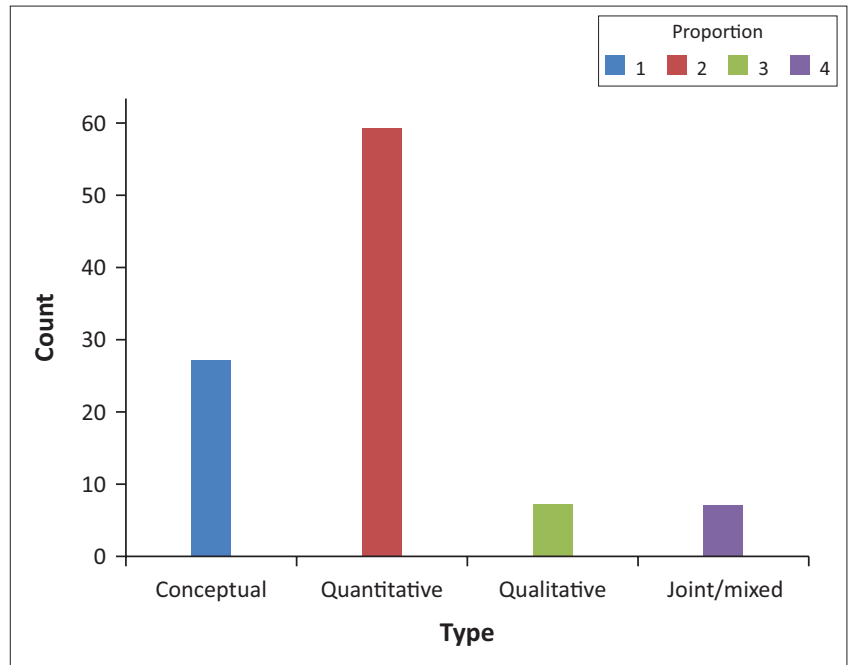

FIGURE 1: Bar chart of trends in research method based on a sample of 25 articles published between 1962 and 2014.

'mixed' methodologies in their work less often than 'quantitative' and 'conceptual' methodologies. This trend has implications for the maturation of leadership-follower research.

There is a need to close the gap between qualitative and quantitative research methods and to integrate their use rather than separate them (Carlie \& Christensen 2004). Research methods should be used with mindfulness - with qualitative methods being used to observe social and human problems, followed by quantitative methods to test inductively formulated followership theories. International trends in leadership-followership research should be assessed to examine the relative use of qualitative and quantitative research methods in the extant literature.

The question can now be asked: 'So what?' Researchers can use any method they want to, as long as it is done in scholarly ways. This researcher encourages the reader to think again. As mentioned in paragraph 1 of this conclusion, this trend has implications for the maturation of leadership-followership research. We want our research to respond to the needs of the populations who benefit from it. The aim of any method is to impart the greatest possible relevant meaning

It is particularly important in the context of diverse cultures that local attempts to formulate authentic theory development will remain both difficult and unsuccessful until endogenous management systems are established and institutionalised. This is very important in the case of South African followership scholars who may well believe that an affinity for qualitative methodology affords the opportunity for meaningful emic research rather than merely testing theories and constructs that may not capture local followership phenomena.

The question now is that, if 'qualitative' and 'joint' research are so important in theory building, why are so few researchers employing these methodologies? A number of authors suggest that quantitative research is more likely to find acceptance in academic journals because statistical 
methods are viewed as more rigorous and reliable while qualitative methodologies appear more open to bias and subjectivity (Argyris 1980).

Both qualitative research and mixed research require good group and interpersonal facilitation skills. In addition, both preclude the gathering of aggregate data and demand longterm commitment from researchers. Qualitative research often requires in-depth study of the history, culture and language of the people one is investigating (Triandis \& Gelfand 1998). Lee (1995) states that interviewing via focus groups and structured interviews can be very difficult to perform and be emotionally draining (Harari \& Beaty 1990).

Researchers are encouraged to be mindful when selecting research paradigms and methods, and this researcher pleads that we take cognisance of Peshkin (1993) who states that:

Qualitative research studies typically serve one or more of the following purposes:

- Description: They can reveal the multifaceted nature of certain situations, settings, processes, relationships systems and people.

- Interpretation: They enable a researcher to (1) gain new insights about a particular phenomenon, and (2) develop new concepts or theoretical perspectives about the phenomenon, and/or (3) discover problems that exist within the phenomenon.

- Verification: They allow the researcher to test the validity of certain assumptions, claims, theories, or generalisations within real-world contexts.

- Evaluation: They provide a means through which a researcher can judge the effectiveness of particular policies, practices, or innovations.

\section{Recommendations}

Research on followership is relatively unexplored and is, to some extent, ignored because of the overwhelming focus on leadership. It is evident from Table 1 and the conclusions and implications therein that:

- A pilot study making use of qualitative and mixed method research could be launched in South Africa to test follower experiences of leader behaviour in a setting where follower-leader dynamics are critical.

- A study could be initiated using the same data as the foregoing archival study to produce a meta-analysis of the relevance of the keywords as possible constructs, and a principal components analysis to determine the possible variables and latent variables that inform the concept of followership.

- A strategic decision should be made by this researcher, or by scholars interested in followership research, to continue with theory-building of followership - possibly through doctoral research to develop a contextual social exchange framework of the dynamics of follower-leader behaviour.

\section{Acknowledgements}

All international researchers who paved the way in follower studies that made it possible for this particular study to have been done.

\section{Competing interests}

The author declares that he has no financial or personal relationships that may have inappropriately influenced him in writing this article.

\section{References}

Antelo, A., 2010, Lecture on "Assessing effective attributes of followers in a leadership process", Health Administration Press, New York.

Argyris, C., 1980, The inner contradictions of rigorous research, Harper and Row, New York.

Avolio B.J. \& Gibbons, T.C., 1988, 'Developing transformational leaders: A life span approach', in J.A. Carlie, P.R. \& C.M. Christensen (eds.), The cycles of theory building in management research, unpublished manuscript.

Bass, B.M., 1981, Stogdill's handbook of leadership, The Free Press, New York.

Blake, R.R. \& Mouton, J.S., 1985, The managerial grid III, Gulf, Houston, TX.

Bligh, M.C., Kohles, J.C., Pearce, C.L., Justin, J.E. \& Stovall, J.F., 2007, 'When the romance is over: Follower perspectives of aversive leadership', Applied Psychology: An International Review 56(4), 528-557. https://doi.org/10.1111/j.1464-0597. 2007.00303.x

Brown, A.D. \& Thornborrow, W.T., 1996, 'Do organizations get the followers they deserve?', Leadership \& Organizational Development Journal 17(1), 5-11. https:// doi.org/10.1108/01437739610105986

Clifford, C. \& Cohn, T.S., 1964, 'The relationship between leadership and personality attributes perceived by followers', master's thesis, American Psychological Association, Washington, DC.

Cresswell, J.W., 2003, Research design: Qualitative, quantitative, and mixed methods approaches, Sage, Thousand Oaks, CA.

Danserieu, F., Graen, G.B. \& Haga, W., 1975, 'A vertical dyad linkage approach to leadership in formal organizations', Organizational Behaviour and Human Performance 13, 46-78. https://doi.org/10.1016/0030-5073(75)90005-7

Eagly, A.H., 2005, 'Achieving relational authenticity in leadership: Does gender matter?', The Leadership Quarterly 16, 459-474. https://doi.org/10.1016/j.leaqua.2005.03.007

Eden, D. \& Leviathan, U., 1975, 'Implicit leadership theory as a determinant of the factor structure underlying supervisory behavior scales', Journal of Applied Psychology 60, 736-741. https://doi.org/10.1037/0021-9010.60.6.736

Evans, M.G., 1970, 'The effects of supervisory behavior on the path-goal relationship', Organizational Behaviour and Human Performance 5, 277-298. https://doi. org/10.1016/0030-5073(70)90021-8

Feldman, J.A. \& Joubert, C.G., 2010, The effect of leadership behaviours on followers' experiences and experiences in a safety-critical industry, South African Journal of Economic and Management Sciences, Vol 20, No 1.

Felfe, J. \& Schyns, B., 2009, Followers' personality and perception of transformationa leadership: Further evidence for the similarity hypothesis, British Academy of Management, Blackwell Publishing Company, Hoboken, NJ.

Fiedler, F.E., 1964, 'A contingency model of leadership effectiveness', in L. Berkowitz (ed.), Advances in experimental social psychology 1, 149-190. https://doi.org/ 10.1016/S0065-2601(08)60051-9

Fiedler, F.E., 1967, A theory of leadership effectiveness, McGraw-Hill, New York.

Fiedler, F.E. \& Garcia, J.E., 1987, New approaches to leadership: Cognitive resources and organizational performance, John Wiley, New York.

Fisher, B.A., 1985, 'Leadership as medium: Treating complexity in group communication research', Small Group Research 16, 167-196. https://doi.org/10.1177/10464 9648501600204

Gardner, W.L., Avolio, B.J., Luthans, F., May, D.R. \& Walumba, F.O., 2005, “'Can you see the real me?" A self-based model of authentic leader and follower development' Leadership Quarterly 16, 343-372. https://doi.org/10.1016/j.leaqua.2005.03.003

George, B. \& Sims, P., 2007, True north: Discovering your authentic leadership, JosseyBass, San Francisco, CA

Graen, G.M. \& Uhl-Bien, M., 1995, 'Relationship-based approach to leadership: Development of leader-member exchange (LMX) theory of leadership over 25 years: Applying a multi-level, multi-domain perspective', Leadership Quarterly 6 , 219-247. https://doi.org/10.1016/1048-9843(95)90036-5

Gravetter, E.J. \& Wallnau, L.B., 2000, Statistics for the behavioural science, 5th edn. Wadsworth/Thomson, Belmont, CA.

Greyvenstein, H. \& Celliers, F., 2012, 'Followership's experiences of organizational leadership: A systems psychodynamic perspective', SA Journal of Industria Psychology 38(2), Art. \#1001, 10 pages. https://doi.org/10.4102/sajip.v38i2.1001

Hackman, J.R., 2002, Leading teams: Setting the stage for great performances, Harvard Business School Press, Boston, MA. 
Harari, O. \& Beaty, D.T., 1990, 'On the folly of relying solely on a questionnaire in crosscultural research', Journal of Managerial Issues 12(3), 24-32.

Harms, P.D. \& Spain, S.M., 2014, 'Follower perceptions deserve a closer look', Industrial and Organizational Psychology 7(2), 187-191. https://doi.org/10.1111/ iops.12130

Hersey, P., Blanchard, K.H. \& Johnson, D.E., 2012, Management of organizational behavior: Leading human resources, 10th edn., Prentice Hall, Englewood Cliffs, NJ.

Hollander, E.P., 1995, 'Ethical challenges in the leader-follower relationship', Business Ethics Quarterly 5(1), 55-65. https://doi.org/10.2307/3857272

House, R.J., 1971, 'A path-goal theory of leader effectiveness', Administrative Science Quarterly 16, 321-328. https://doi.org/10.2307/2391905

House, R.J. \& Dessler, G., 1974, 'The path-goal theory of leadership: Some post hoc and a priory tests', in J. Hunt \& L. Larson (eds.), Contingency approaches in leadership, pp. 29-55, Southern Illinois University Press, Carbondale, IL.

Jaussi, S.K. \& Dionne, S.D., 2004, 'Unconventional leadership behaviour, subordinate satisfaction, effort and perception of leader effectiveness', Journal of Leadership and satisfaction, effort and perception of leader effectiveness', Journal of Leadership and
Organizational Studies 10(5), 15-26. https://doi.org/10.1177/107179190401000302

Jooste, C. \& Fourie, B., 2009, 'The role of strategic leadership in effective strategy implementation: Perceptions of South African strategic leaders', South African Business Review 13(3), 51-67.

Katz, R.L., 1974, 'Skills of an effective administrator', Harvard Business Review 52, 90-102.

Kelley, R.E., 1992, The power of followership: How to create leaders people want to follow, and followers who want to lead themselves, Doubleday, New York.

Kilburn, B.R., 2010, 'Identifying effective followers: A review of typologies', International Journal of the Academic Business World 4(1), 9-19.

Kinlaw, D.C., 1998, Superior teams: What they are and how to develop them, Grove, Hampshire, UK.

Lapierre, L.M. et al., 2012, 'Strength in numbers: How employees' acts of followership can influence their manager's charismatic leader', Zeitschrift fur Psychologie $220(4), 2604 / a 000119$

Lee, G.J., 2013, 'Synthesis between leadership behaviours and principal-agent theory' Southern African Business Review 17(3), 101-130.

Lord. G., De Vader, C.L. \& Alliger, G.M., 1986, 'A meta-analysis between personality traits and leadership: An application of validity generalization procedures', Journa of Applied Psychology 71, 402-410. https://doi.org/10.1037/0021-9010.71.3.402

Malakian, P., 2014, 'Followership in leadership studies: A case of leader-follower trade approach', Journal of Leadership Studies 7(4), 6-22. https://doi.org/10.1002/jls.21306

Mossholder, K.W., Niebuhr, R.E. \& Norris, D.R., 1990, 'Effects of dyadic duration on the relationship between leader behavior perceptions and follower outcomes', Journal of Organizational Behavior 11, 379-388. https://doi.org/10.1002/job. 4030110505
Mumford, M.D., Zaccaro, S.J., Harding, F.D., Jacobs, O.T. \& Fleishman, E.A., 2000, 'Leadership skills for a changing world: Solving complex social problems', Leadership Quarterly 11, 11-35. https://doi.org/10.1016/S1048-9843(99)00041-7

Opperman, M., 2000, 'Triangulation of methodological discussion', International Journal of Tourism Research 2(2), 141-147. https://doi.org/10.1002/(SICI)1522 1970(200003/04)2:2<141::AID-JTR217>3.0.CO;2-U

Parmer, L., Green, M., Duncan, P. \& Zarate, C., 2013, 'The relationship between followers' personality and preferences in leadership', Journal of Leadership, Accountability and Ethics 10(2), 55-64.

Peshkin, A., 1993, 'The Goodness of Qualitative Research', Educational Researcher 22(2), 23-29.

Peus, C., Braun, S. \& Frei, D., 2012, 'The role of follower attributions in adverse leadership - A multilevel model', Zeitschrift fur Psychologie 220(4), 241-250. https://doi.org/10.1027/2151-2604/a000118

Phillips, A.S. \& Bedeian, A.G., 1994, 'Leader-follower exchange quality: The role of personal and interpersonal attributes', Academy of Management Journal 37(4), 2-9. https://doi.org/10.2307/256608

Prilipco, E.V., Antelo, A. \& Henderson, R.L., 2011, 'Rainbow of followers' attributes in a leadership process', International Journal of Management and Information Systems 15(2), 79-94. https://doi.org/10.19030/ijmis.v15i2.4157

Ridley, S.S., Chattergee, S.R. \& Soutar, G., 1998, 'Followers perceptions of leaders: Some Australian evidence', International Journal of Employment Studies 6(2), 71-90.

Schyns, B. \& Hansborough, T., 2008, 'Why the brewery ran out of beer: The attribution of mistakes in a leadership context', Social Psychology 39, 197-203. https://doi. org/10.1027/1864-9335.39.3.197

Singh, N. \& Bodhania, S., 2013, 'Followership in contemporary organizations: A South African perspective', Journal of Contemporary Management 10 498-516.

Steinbauer, R. et al., 2013, 'Ethical leadership and followers' moral judgement: The role of followers' perceived accountability and self-leadership', Journal of Business Ethics 120, 381-392. https://doi.org/10.1007/s10551-013-1662-x

Thoroughgood, C.N., Hunter, T.H. \& Sawyer, K.B., 2011, 'Examination of contextual influence on follower perceptions and reactions to aversive leadership',
Journal of Business Ethics 100, 647-672. https://doi.org/10.1007/s10551-010Journal

Triandis, H.C. \& Gelfand, M.J., 1998, 'Converging measurement of horizontal and vertical individualism and collectivism', Journal of Personality and Social Psychology 74(2), 118-128. https://doi.org/10.1037/0022-3514.74.1.118

Vecchio, R.P., 2002, 'Leadership and gender advantage', The Leadership Quarterly 13, 643-671. https://doi.org/10.1016/S1048-9843(02)00156-X

Wiley, C., 1997, 'What motivates employees according to 40 years of motivationa surveys', International Journal of Manpower 18(3), 263-280. https://doi.org/ 10.1108/01437729710169373 